\title{
Platinum-carbon black-titanium dioxide nanocomposite electrocatalysts for fuel cell applications ${ }^{\dagger}$
}

\author{
SATHEESH SAMBANDAM ${ }^{1}$, VINODH VALLURI ${ }^{2}$, WILAIWAN CHANMANEE ${ }^{2}$, \\ NORMA R DE TACCONI ${ }^{2}$, WESLEY A WAMPLER ${ }^{3}$, WEN-YUAN LIN ${ }^{3}$, \\ THOMAS F CARLSON ${ }^{3}$, VIJAY RAMANI ${ }^{1, *}$ and KRISHNAN RAJESHWAR ${ }^{2} *$ \\ ${ }^{1}$ Center for Electrochemical Science and Engineering, Department of Chemical Biological Engineering, \\ Illinois Institute of Technology, Chicago, Illinois 60616, USA \\ ${ }^{2}$ Center for Renewable Energy Science and Technology (CREST), University of Texas at Arlington, \\ Arlington, TX 76019, USA \\ ${ }^{3}$ Sid Richardson Carbon and Energy Company, Fort Worth, TX 76106, USA \\ e-mail: ramani@iit.edu; rajeshwar@uta.edu
}

\begin{abstract}
New-generation $\mathrm{Pt} / \mathrm{C}-\mathrm{TiO}_{2}$ nanocomposite electrocatalysts for fuel cells, prepared by a heterogeneous photocatalytic method, have been characterized using techniques such as cyclic voltammetry, rotating disk electrode (RDE) voltammetry, and electrochemical impedance spectroscopy (EIS). Importantly, galvanostatic data confirm the superior stability of these materials against corrosion under anodic polarization conditions relative to commercial benchmark fuel cell electrocatalysts. EIS spectra from ETEK 5, SIDCAT 405 and SIDCAT 410 membrane electrode assemblies (MEAs) were fit to a Randles equivalent circuit with a Warburg element to show the presence of $\mathrm{O}_{2}$ transport limitation arising from the use of thicker electrodes (lower Pt loading on carbon). The use of a constant phase element (CPE) instead of pure capacitor was justified from the fit procedure as CPE represents the porous electrode system more precisely with its distributive elements. EIS spectra from Tanaka, SIDCAT 451 and SIDCAT 452 MEAs (thinner electrodes) were fit to a Randles circuit with a pure capacitor and no Warburg element. The use of a transmission line model for fitting these data independently provided information about the catalyst layer resistance while all other parameters matched well with that of the Randles circuit. The effective proton transport in cathodes was quantified using polarization data for both classes of MEAs. Trends in the previously reported performance of MEAs prepared using these electrocatalysts were justified based on the relative contributions of kinetic, Ohmic and mass transfer losses to the overall overpotential, which in turn were estimated from impedance and polarization data analyses.
\end{abstract}

Keywords. Electrochemical impedance spectroscopy; membrane electrode assembly; electrochemically active surface area; oxygen reduction reaction; polymer electrolyte fuel cell.

\section{Introduction}

A major technology roadblock to widespread deployment of polymer electrolyte fuel cells (PEFCs) relates to cost and durability issues. The cost factor mainly relates to the platinum content of the electrocatalyst while the durability issue is more complex and involves at least three sub-set problems as outlined in figure 1. Our three-pronged collaborative project has addressed both these issues via the development of a new family of platinum-carbonblack-titanium dioxide nanocomposites for use in PEFCs. ${ }^{1,2}$ These photocatalytically prepared nano-

\footnotetext{
${ }^{\dagger}$ Dedicated to the memory of the late Professor S K Rangarajan *For correspondence
}

composite samples have finely dispersed and catalytically active platinum clusters uniformly distributed throughout the nanocomposite structure resulting in better platinum utilization. The presence of small amounts of an oxide semiconductor such as titanium dioxide $\left(\mathrm{TiO}_{2}\right)$ results in the quenching of reactive oxygen species resulting from the electroreduction of dioxygen $\left(\mathrm{O}_{2}\right)$; this then translates to enhanced membrane stability as probed by fluoride emission tests. $^{2}$

In this paper, we build on these initial data with more extensive characterization of our nanocomposite electrocatalysts. Aside from the usual suite of electrochemistry tools, electrochemical impedance spectroscopy (EIS) was also used in this study. This technique has been used before to probe processes 
occurring across a wide range of timescales in PEFCs. ${ }^{3-5}$ The strategy most commonly used to extract meaningful parameters from the impedance data is to fit the EIS data against an equivalent circuit model to estimate individual contributions from each fuel cell component (membrane, electrode, gas diffusion layers, etc) to the overall impedance. In this study of platinum-carbon-black-titanium dioxide (hereafter designated as: $\mathrm{Pt} / \mathrm{C}-\mathrm{TiO}_{2}$ ) electrocatalysts, EIS spectra were recorded for a fuel cell operating in the $\mathrm{H}_{2} / \mathrm{O}_{2}$ mode using a two-electrode configuration with the anode acting as a pseudoreference electrode. Values for the membrane resistance, electrode capacitance and charge transfer resistance were extracted by fitting the impedance data against an equivalent circuit model.

\section{Materials and methods}

\subsection{Preparation of $\mathrm{Pt} / \mathrm{C}-\mathrm{TiO}_{2}$ nanocomposite}

Details are given elsewhere. ${ }^{2}$ Briefly, commercially available carbon blacks and $\mathrm{TiO}_{2}$ (Degussa P-25) were mixed in a pre-selected wt $\%$ ratio and dispersed in $50 \mathrm{~mL}$ of deionized water (Corning Megapure) with the aid of an ultrasonic bath. The dispersion was then transferred to a $500 \mathrm{~mL}$ volumetric flask where $13.5 \mathrm{~mL} \mathrm{HCOOH} \mathrm{(96 \% )} \mathrm{and} \mathrm{the} \mathrm{required} \mathrm{amount} \mathrm{of}$ platinum salt precursor $\left(\mathrm{K}_{2} \mathrm{PtCl}_{6}, \mathrm{Pt} 40 \cdot 11 \%\right.$, Alfa Aesar) to generate different $\mathrm{Pt}$ wt $\%$, ranging from 5 to 50 , were added and then the total volume was adjusted to $500 \mathrm{~mL}$. It was then poured into a UV photoreactor ${ }^{6}$ and kept with constant $\mathrm{N}_{2}$ bubbling to

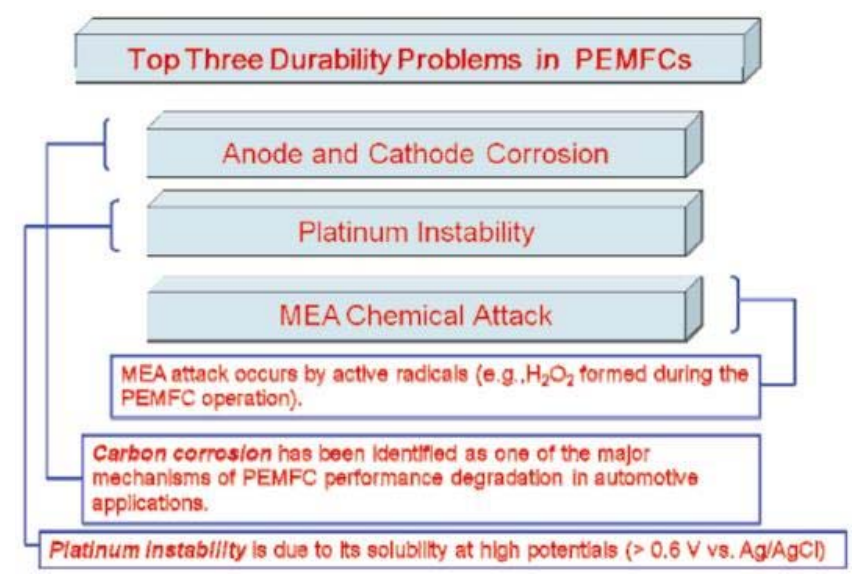

Figure 1. The three most important durability issues to be addressed in PEM fuel cells. Each sub-set problem is also identified. enhance the particle dispersion in the solution. The $\mathrm{N}_{2}$ gas spurge was maintained during the photoirradiation. After completing the photoreaction, the resultant $\mathrm{Pt} / \mathrm{C}-\mathrm{TiO}_{2}$ catalyst was filtered, washed and dried overnight at $70^{\circ} \mathrm{C}$. $\mathrm{Pt}-\mathrm{CTiO}_{2}$ catalysts were prepared with different $\mathrm{Pt} w \mathrm{wt} \%$ ranging from 5 to 50 and the amount of $\mathrm{TiO}_{2}$ was also varied from $5 \%$ to $10 \%$ (see table 1). Several carbon blacks provided by Sid Richardson Carbon and Energy Company as well as other commercially available blacks were used in the photocatalytic preparation of $\mathrm{Pt} / \mathrm{C}-\mathrm{TiO}_{2}$ composites. Other samples used as benchmarks are also included in table 1 .

\subsection{Physical characterization}

Transmission electron microscopy (TEM) images (Zeiss Model EM902) were used to assess the Pt dispersion on the carbon or $\mathrm{C}-\mathrm{TiO}_{2}$ support.

\subsection{Electrochemical measurements}

The ex situ electrochemical characterization of different $\mathrm{Pt} / \mathrm{C}-\mathrm{TiO}_{2}$ catalysts consisted of cyclic voltammetry and rotating disk electrode (RDE) measurements; all these experiments were conducted in a glass cell at laboratory temperature $\left(25^{\circ} \mathrm{C}\right)$. For this purpose, $\mathrm{Pt} / \mathrm{C}-\mathrm{TiO}_{2}$ composite catalyst powders were deposited in the form of a thin film on glassy carbon (GC) disk electrodes. Coating was performed with $20 \mu \mathrm{L}$ catalyst ink that was prepared as follows: $1 \mathrm{mg}$ of catalyst was dispersed in $1 \mathrm{~mL}$ of water-isopropanol solution $(80: 20$ volume ratio) with 10 min ultrasonication to create a uniform dispersion in the solvent. Then, $10 \mu \mathrm{L}$ of $5 \%$ Nafion $^{\circledR}$ solution was added to the dispersion and additional ultrasonication was performed for 5 more min to have a well dispersed ink. Immediately after the final ultrasonication, $20 \mu \mathrm{L}$ of ink was placed on the GC disk electrode (geometrical area $=0.196 \mathrm{~cm}^{2}$; freshly polished with $0.1 \mu \mathrm{m}$ alumina slurries and cleaned also by sonication in deionized water for $2 \mathrm{~min}$ ) and completely dried. The ink on top of the GC electrode was allowed to dry at room temperature in $\mathrm{N}_{2}$ atmosphere. The thickness of the resulting coated film, calculated using the density of $\mathrm{Nafion}^{\circledR}$, was in the range of $0.05-0.08 \mu \mathrm{m}$.

Cyclic voltammetry (CV) experiments were performed to determine the electrochemically active surface area (ECA) of the thin film catalysts. A scan rate of $20 \mathrm{mV} \mathrm{s}^{-1}$ was used to sweep the working 
Table 1. Comparative composition and carbon black source of photocatalytically prepared $\mathrm{Pt} / \mathrm{C}-\mathrm{TiO}_{2}$ samples as well as other $\mathrm{Pt} / \mathrm{C}$ and $\mathrm{Pt} / \mathrm{TiO}_{2}$ controls.

\begin{tabular}{lccc}
\hline Sample & wt\% Pt & wt $\% \mathrm{TiO}_{2}$ & Type of carbon \\
\hline Electrocatalysts with low Pt loading on Carbon (Set I) & \\
SIDCAT 405 & 5 & 5 & FC400, SidRich \\
SIDCAT 410 & 10 & 5 & FC400, SidRich \\
SIDCAT 420 & 20 & 5 & FC400, SidRich \\
ETEK 5 (benchmark) & 5 & 0 & Vulcan XC-72 \\
& & & \\
Electrocatalysts with high Pt loading on Carbon (Set II) & \\
SIDCAT 451 & 50 & 5 & FC400, SidRich \\
SIDCAT 452 & 50 & 10 & FC400, SidRich \\
Tanaka (benchmark) & 46.5 & 0 & TKK \\
ETEK 50 (benchmark) & 50 & 0 & Vulcan XC-72 \\
DYNALYST (benchmark) & 60 & 0 & - \\
\hline
\end{tabular}

${ }^{a}$ SIDCAT $4 X X$ (with $X=05,10,51$, and 52) are new trademark names for Pt/C-TiO composites from Sid Richardson Carbon and Energy Co

electrode potential from 0.70 to $-0.24 \mathrm{~V}$ (vs $\mathrm{Ag} /$ $\mathrm{AgCl})$ and back. The ECA was estimated from averaging the area under the hydrogen adsorption and desorption peaks in the $\mathrm{CV}{ }^{7}$.

RDE measurements were performed with a modulated speed rotator (AFMSRCE manufactured by Pine Research Instrumentation) and the rotation rate was adjusted at pre-selected $\omega$ values over the range from 100 to 1500 RPM. Rotation rate accuracy was within $1 \%$. The current/potential profiles at different rotation speeds (or for the stationary electrode) were obtained with an electrochemical analyzer/workstation (CH Instruments Model 600C). A platinum coil, placed in a separate compartment, served as counterelectrode and a saturated $\mathrm{Ag} / \mathrm{AgCl} / \mathrm{satd}$. $\mathrm{KCl}$ electrode was used as reference electrode. The oxygen reduction reaction (ORR) was studied in $0.1 \mathrm{M}$ $\mathrm{HClO}_{4}$ (A.C.S. reagent, Fisher Scientific Company) saturated with $\mathrm{O}_{2}(99.9 \%)$ using a scan rate of $10 \mathrm{mV} \mathrm{s}^{-1}$ from $0.8 \mathrm{~V}$ to $-0.1 \mathrm{~V}$ while the electrode was rotated at selected $\omega$ values.

Films prepared for galvanostatic polarization tests follow a different procedure than that used for the ECA and RDE experiments detailed above. Film preparation now followed the procedure used for carbon corrosion tests of catalysts with MEAs, i.e. the catalyst loadings on the electrode (glassy carbon, $0.196 \mathrm{~cm}^{2}$ ) were controlled at $0.4 \mathrm{mg} / \mathrm{cm}^{2}$ and the galvanostatic tests were performed at selected current values (nominally $1 \mathrm{~mA} / \mathrm{cm}^{2}$ ) in agreement with industry protocol. ${ }^{8}$ The catalyst ink was prepared by dispersing appropriate amount of catalyst (to satisfy a loading of $\left.0.4 \mathrm{mg} / \mathrm{cm}^{2}\right)$ in $1 \mathrm{~mL}$ Nafion $(5 \% \mathrm{w} / \mathrm{w})$ by $15 \mathrm{~min}$ sonication to create a uniform dispersion. Then, coating of a glassy carbon electrode was performed from the ink freshly ultrasonicated and using appropriate aliquots to control the catalyst loaded on the electrode. As example, for SIDCAT 452, the ink was prepared with $10 \mathrm{mg}$ of catalyst dispersed in the Nafion solution and then $10 \mu \mathrm{L}$ of ink was placed on a the electrode surface and allow it dry in a container under $\mathrm{N}_{2}$ atmosphere. Then the electrode was galvanostatically tested by imposing a constant current density $\left(1 \mathrm{~mA} / \mathrm{cm}^{2}\right.$ or $\left.0.4 \mathrm{~mA} / \mathrm{cm}^{2}\right)$ in $0.1 \mathrm{M}$ $\mathrm{HClO}_{4}$ and measuring the cell voltage profile vs time (see figure 6 below).

\subsection{Preparation of membrane electrode assemblies (MEAs)}

MEAs were prepared with $\mathrm{Pt} / \mathrm{C}$ and $\mathrm{Pt} / \mathrm{C}-\mathrm{TiO}_{2}$ catalysts at the anode and cathode. The proton conducting membrane used in all MEAs was Nafion ${ }^{\circledR} 112$. Two sets of electrocatalysts were studied, as listed in table 1. The first set of electrocatalysts (SIDCAT 405 and SIDCAT 410) had low Pt loadings and was used for preliminary studies. Based on the promising results obtained, a second set of electrocatalysts was formulated with more realistic (from a fuel cell application standpoint) $\mathrm{Pt}$ loadings of $50 \mathrm{wt} \%$. Because the synthesis procedure employed in our study precluded preparation of samples without the presence of photocatalyst $\left(\mathrm{TiO}_{2}\right), 5 \mathrm{wt} \% \mathrm{Pt} / \mathrm{C}$ catalyst was procured from E-TEK and $46.5 \mathrm{wt} \% \mathrm{Pt} / \mathrm{C}$ catalyst was procured from TKK (Japan). These $\mathrm{TiO}_{2}$ - free electrocatalysts served as benchmarks 
for each set (i.e. with low and high Pt loading on carbon support) of nanocomposite $\mathrm{Pt} / \mathrm{C}-\mathrm{TiO}_{2}$ catalysts studied.

MEAs were prepared by spraying successive layers of the catalyst ink directly onto either side of a Nafion ${ }^{\circledR} 112$ membrane. An infrared lamp was used to dry the MEA prior to the application of each layer. A polytetrafluoroethylene (PTFE) mask was employed to maintain the active area of the MEA at $5 \mathrm{~cm}^{2}$. After both the anode and cathode catalyst layers were applied, the MEA was hot-pressed at $120^{\circ} \mathrm{C}$ and $2.75 \mathrm{MPa}$. The Pt loading of each electrode was gravimetrically maintained at $0.4 \pm$ $0.05 \mathrm{mg} \mathrm{cm}^{-2}$ at the cathode and $0.2 \pm 0.02 \mathrm{mg} \mathrm{cm}^{-2}$ at the anode.

\subsection{Electrochemical impedance spectroscopy}

Electrochemical impedance spectra were recorded using a Solartron frequency response analyser (model 1252A) and potentiostat (model 1470). Spectra were recorded for MEAs operating in the $\mathrm{H}_{2} / \mathrm{O}_{2}$ mode at $80^{\circ} \mathrm{C}$ and $75 \%$ relative humidity (RH) (anode and cathode) with a constant reactant flow rate of $200 \mathrm{cc} / \mathrm{min}$. The fuel cell cathode served as the working electrode and the fuel cell anode served as the counter and pseudoreference electrode. A galvanostatic AC signal was applied in the frequency range $20 \mathrm{kHz}$ to $1 \mathrm{~Hz}$, with a base current of $50 \mathrm{~mA}$ $\mathrm{cm}^{-2}$ and amplitude of $2 \mathrm{~mA} \mathrm{~cm}$. The data obtained were fitted to a Randles circuit with and without a finite Warburg impedance component. In some cases, the data were also fit to a transmission line equivalent circuit model. ${ }^{4}$ ZVIEW software (Version 2.9, Scribner Associates, Inc.) was used for fitting/ simulation of data to estimate the high frequency resistance (HFR), double layer capacitance $\left(C_{d l}\right)$, catalyst layer resistance $\left(R_{c l}\right)$ and charge transfer resistance $\left(R_{c t}\right)$ in the MEAs.

\subsection{Other electrochemical characterization on MEAs}

Steady state polarization data was obtained at $80^{\circ} \mathrm{C}$ and $75 \% \mathrm{RH}$ (anode and cathode) in the $\mathrm{H}_{2} / \mathrm{O}_{2}$ and $\mathrm{H}_{2}$ /air modes for the MEAs prepared with selected electrocatalysts shown in table 1 . These data were analysed to estimate the relative contributions of various sources of overpotential (i.e. kinetic, Ohmic and mass transport losses) using methods summarized in the literature. ${ }^{9,10}$ The contributions of two sources of Ohmic polarization: (i) membrane + contact resistance, and (ii) electrode resistance were estimated.

The membrane + contact Ohmic resistance $\left(R_{m}\right)$ was measured by the current interrupt technique built into the test station. Estimation of electrode Ohmic resistance $\left(R_{e}\right)$ involved calculation of the current ratio (ratio of current density from the $\mathrm{O}_{2}$ to the air polarization curve at the same overpotential in the diffusion limited region of the polarization curve). An iterative procedure was followed to obtain the value of $R_{e}$, which, when used to correct the $\mathrm{O}_{2}$ and air polarization data, yielded a current ratio closest to 4.8 (ratio of oxygen concentration in $\mathrm{O}_{2}$ to air). ${ }^{9,10}$ Iterative methods were also used to determine the limiting current for each oxidant and the $i R$ free polarization data was corrected for non-reacting mass transfer as described in detail elsewhere. ${ }^{9,10}$

\section{Results and discussion}

\section{$3.1 \mathrm{Pt} / \mathrm{C}-\mathrm{TiO}_{2}$ nanocomposite}

Perhaps the most surprising aspect of our new electrocatalysts was the very uniform distribution of the Pt clusters throughout the nanocomposite structure as exemplied by the TEM picture in figure $2 \mathrm{a}$. In contrast, a chemically prepared Pt/carbon black counterpart had an uneven distribution of Pt (figure $2 \mathrm{~b})$. The fact that photocatalysis results in the deposition of Pt even on sites far removed from the oxide could only mean that the initially photogenerated carriers (electrons) on the oxide are efficiently funneled into the carbon black phase as schematically shown in figure 3 . The electronic energy levels (acceptor levels) presumably lie below the $\mathrm{TiO}_{2}$ trap states for this charge mediation mechanism to be operative. ${ }^{11}$

The electrochemically active surface area (ECA) is an important parameter in the characterization of PEFC electrocatalysts and electrodes. The ECA can be calculated from $\mathrm{CV}$ data using the following equation: ${ }^{7}$

$$
\mathrm{ECA}=\frac{Q_{H}}{[\mathrm{Pt}] \mathrm{Q}_{C}},
$$

where $Q_{H}\left(\mathrm{mC} / \mathrm{cm}^{2}\right)$ is the charge transferred under the hydrogen peaks involving 1 electron/platinum stoichiometry, $[\mathrm{Pt}]$ represents the Pt loading in the working electrode and $Q_{C}$ is the electrical charge as- 
sociated with a monolayer adsorption of hydrogen on Pt $\left(0.21 \mathrm{mC} / \mathrm{cm}^{2}\right)$. The $\mathrm{CV}$ traces obtained using the different electrocatalysts (examples of which are contained in figure 4a) were integrated and the resulting ECA data are shown in figure $4 \mathrm{~b}$ as a function of Pt loading in the electrocatalyst. Clearly there is an optimal Pt loading beyond which the ECA (and Pt utilization) suffer (see below).

\subsection{Oxygen reduction reaction (ORR)}

The facile $\mathrm{H}_{2}$ oxidation kinetics at the anode coupled with the slow $\mathrm{O}_{2}$ reduction reaction (ORR) kinetics renders the cathode reaction as the bottleneck
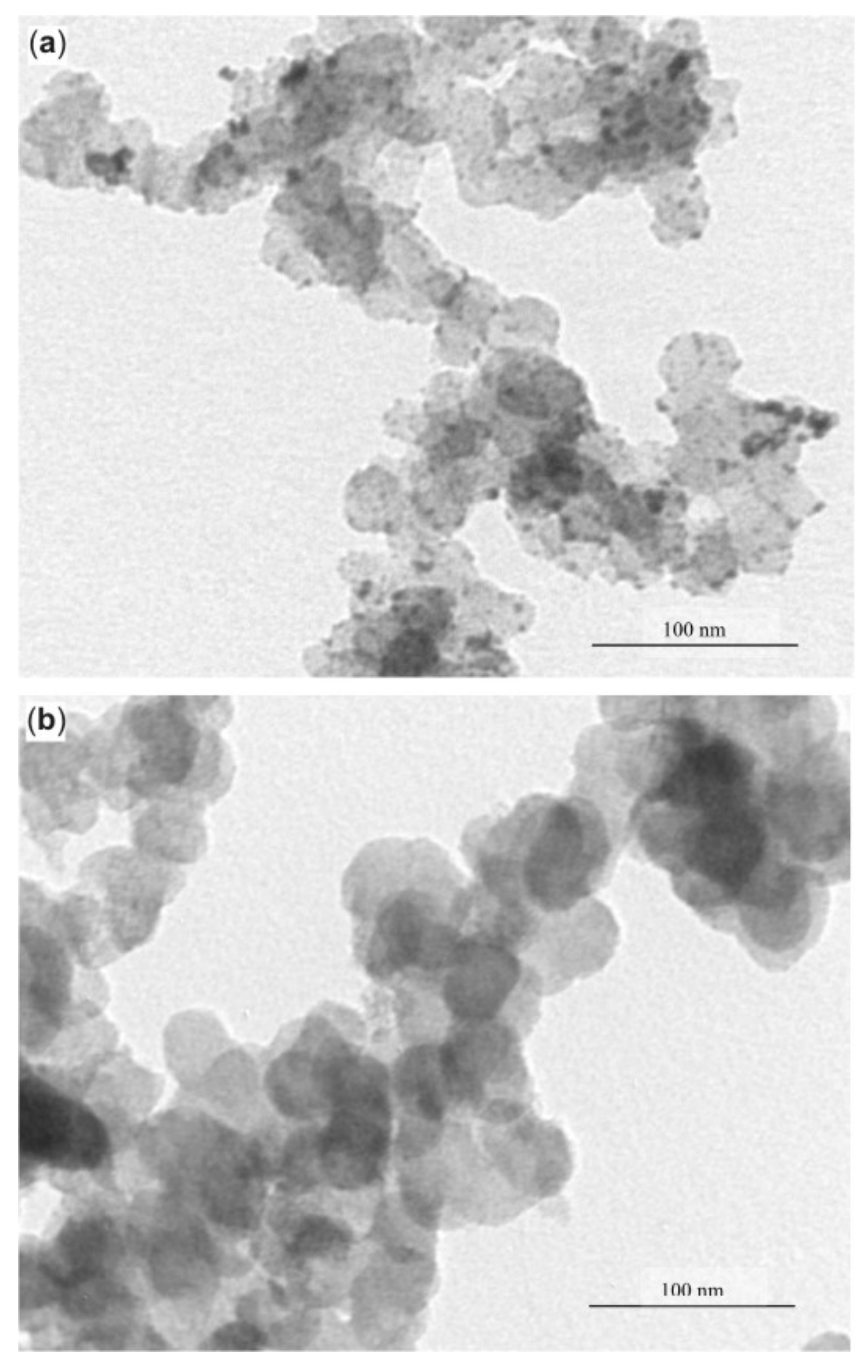

Figure 2. (a) Transmission electron microscope (TEM) image of photocatalytically generated SIDCAT 405 with Pt nanoparticles diameter of $2 \cdot 6 \pm 0.1 \mathrm{~nm}$ as determined by Scherrer analyses at the $\operatorname{Pt}(111)$ and $\operatorname{Pt}(200)$ XRD peaks. (b) TEM image of a platinum-modified carbon electrocatalyst containing also wt $5 \%$ Pt but prepared by a chemical reduction method. in PEFCs ${ }^{12}$ and so attention was focused on the ORR. The ORR kinetics were analysed by RDE voltammetry. ${ }^{13}$ Figure 5 contains representative RDE voltammetry data on four $\mathrm{Pt} / \mathrm{C}-\mathrm{TiO}_{2}$ samples with variable Pt loadings (ranging from $5 \mathrm{wt} \%$ to $50 \mathrm{wt} \%$ ).

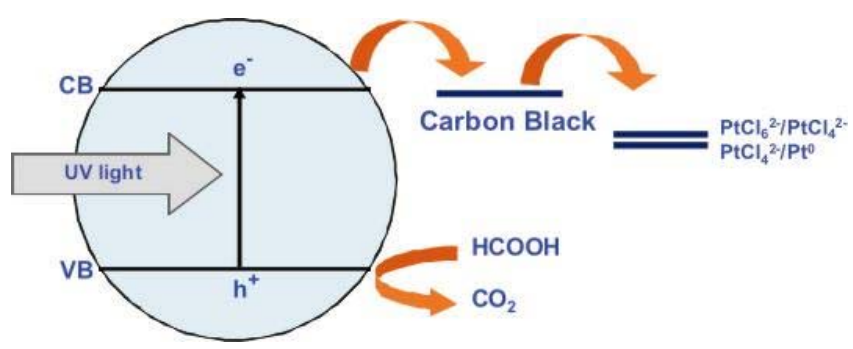

Figure 3. Heterogeneous photocatalytic process used for the preparation of $\mathrm{Pt} / \mathrm{C}-\mathrm{TiO}_{2}$ (SIDCAT) electrocatalysts.
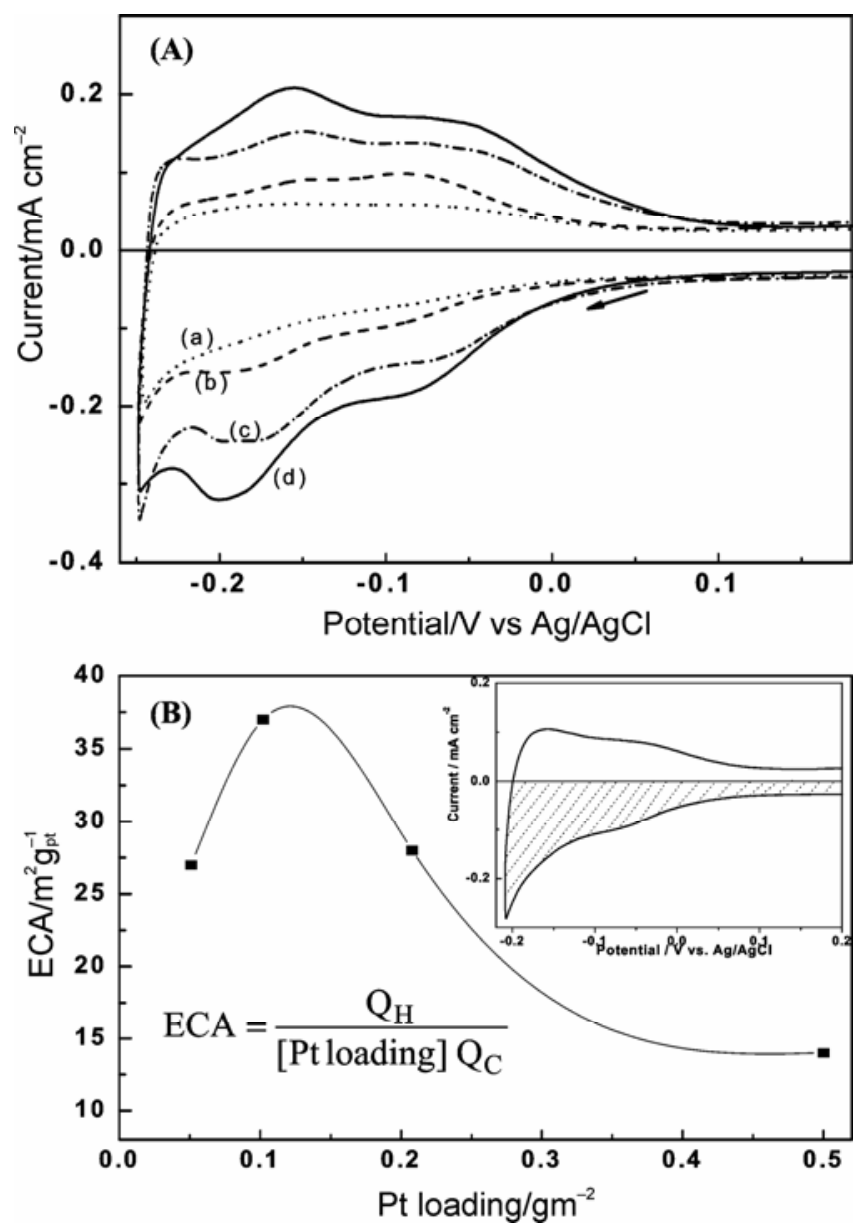

Figure 4. (A) Comparison of the $\mathrm{H}$ adsorption/ desorption voltammetric peaks for SIDCAT 405, (a) SIDCAT 410, (b) SIDCAT 451, (c) and SIDCAT 452 (d) at $20 \mathrm{mV} / \mathrm{s}$ in $\mathrm{N}_{2}$ satd. $0 \cdot 1 \mathrm{M} \mathrm{HClO}_{4}$. (B) ECA as a function of platinum loading. The ECA calculation is exemplified for SIDCAT 420, i.e. containing Pt loading of $0 \cdot 20 \mathrm{~g} / \mathrm{m}^{2}$, in the insert. Integration of the shaded area minus the double-layer charge is used in the determination of $Q_{\mathrm{H}}$. 
There is a clear progression in kinetic facility for the ORR as the Pt content of the electrocatalyst is increased (figure 5). Interestingly, when the $\mathrm{TiO}_{2}$

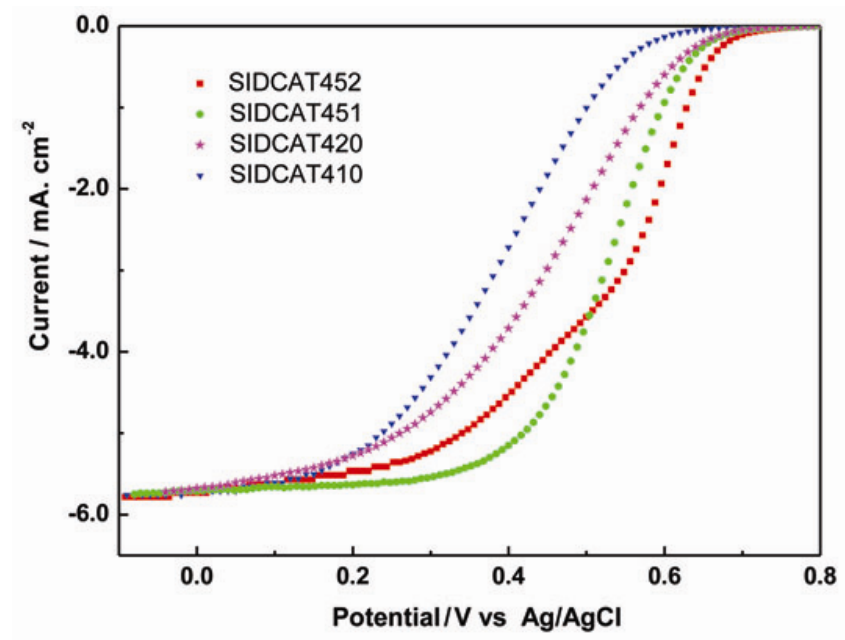

Figure 5. Comparative potentiodynamic oxygen reduction curves for selected SIDCAT electrocatalysts using RDE voltammetry in $\mathrm{O}_{2}$ - sat. $0 \cdot 1 \mathrm{M} \mathrm{HClO}_{4}$ solution at $10 \mathrm{mV} / \mathrm{s}$ with a rotation rate of $1500 \mathrm{RPM}$. For the composition of SIDCAT 410, 420, 451 and 452, see table 1 .

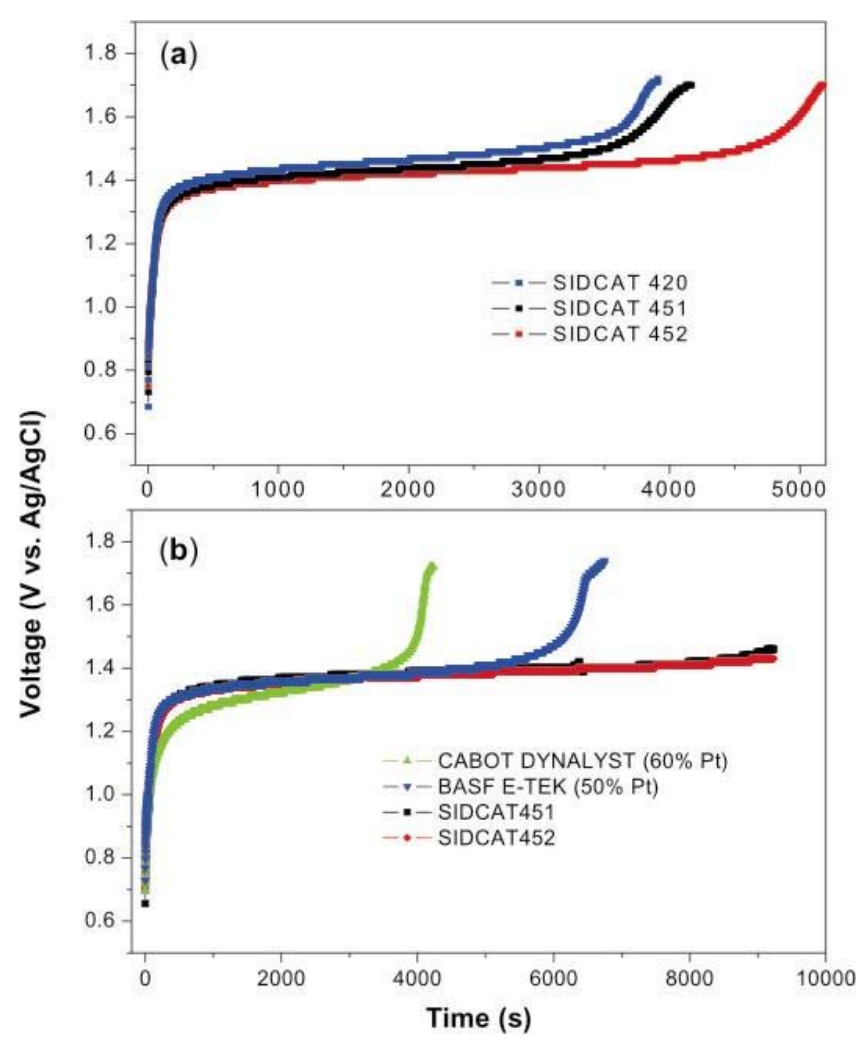

Figure 6. Galvanostatic corrosion tests performed at $1.0 \mathrm{~mA} / \mathrm{cm}^{2}$ (a) and $0.4 \mathrm{~mA} / \mathrm{cm}^{2}$ (b) respectively for SIDCAT 420, 451, 452 and two commercial samples containing $50 \%$ (blue trace in figure $6 \mathrm{~b}$ ) and $60 \% \mathrm{Pt}$ (green trace in figure $6 b$ ). content is increased from $5 \mathrm{wt} \%$ to $10 \mathrm{wt} \%$, there is a further positive shift in the voltammogram although now a break also appears at the half-way point (figure 5). In all the cases, further analyses of these RDE data revealed electron stoichiometry values close to 4 signalling that the ORR on the $\mathrm{Pt} / \mathrm{C}-\mathrm{TiO}_{2}$ surface was by-passing the free radical generating $2 e^{-}$intermediate step. ${ }^{2}$ This finding has positive implications for the PEM stability in the MEA as electrochemically generated hydrogen peroxide is one of the sources of free radical species responsible for PEM degradation in an operating fuel cell (see above).

\subsection{Galvanostatic polarization as durability probe}

Figure 6 contains galvanostatic polarization data at two current densities, 1 and $0.4 \mathrm{~mA} / \mathrm{cm}^{2}$ respectively. When the electrode is initially polarized, the
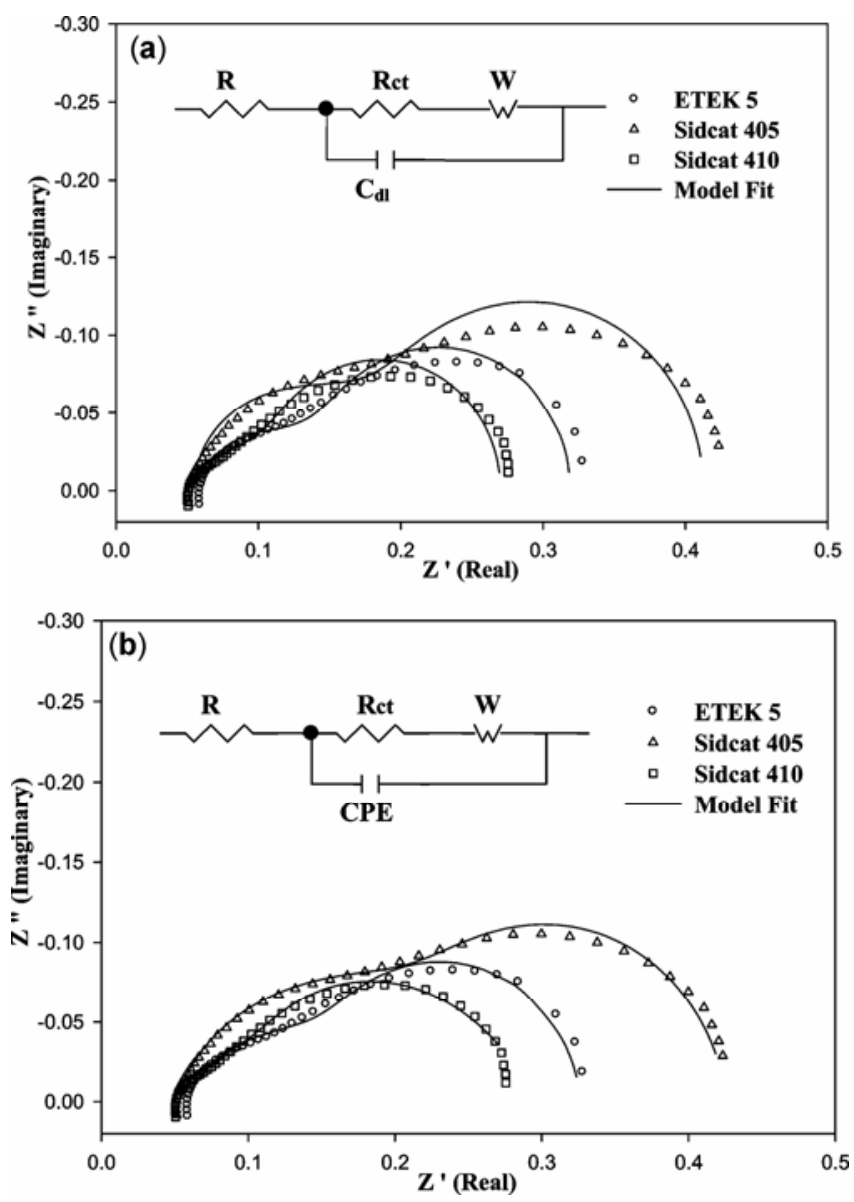

Figure 7. (a and b) Nyquist plots for MEAs prepared with low $\mathrm{Pt}$ loading catalysts under $\mathrm{H}_{2} / \mathrm{O}_{2}$ operation at $80^{\circ} \mathrm{C}$ and $75 \% \mathrm{RH}$ with a constant current of $50 \mathrm{~mA} / \mathrm{cm}^{2}$ and $2 \mathrm{~mA} / \mathrm{cm}^{2}$ amplitude. Points indicate experimental data and lines represent model fits. 
carbon first undergoes corrosion as signalled by the rapid positive excursion of the electrode potential. Then the electrode potential is stabilized for a period of time till the inception of the next corrosion pathway, namely that of the Pt component. This results in a further shift of the potential to more positive values. It must be noted that $\mathrm{Pt}$ has a small but finite solubility under the high electrode potential and oxidizing environment under these polarization conditions. In figure $6 \mathrm{a}$, a higher $\mathrm{TiO}_{2}$ content in the $\mathrm{Pt} / \mathrm{C}-\mathrm{TiO}_{2}$ nanocomposite is significantly seen to stabilize the electrode against Pt corrosion. Similarly a higher Pt content in the electrocatalyst is beneficial from a corrosion perspective in spite of the fact that the ECA is non-optimal (see above).

Very significantly, the new-generation nanocomposite electrocatalysts outperform two different commercial benchmarks in corrosion stability (figure 6b). For polarization periods up to ca. $9000 \mathrm{~s}$, no significant Pt corrosion was noted for both the SIDCAT samples (figure 6b). This performance trend mirrors our earlier observations ${ }^{2}$ of lower fluoride emission rates for these electrocatalysts vis-àvis commercial benchmarks.

\subsection{Electrochemical impedance spectroscopy}

AC impedance spectra are shown (as Nyquist plots) in figures 7 and 8 for the MEAs operating at $80^{\circ} \mathrm{C}$ and $75 \% \mathrm{RH}$. The high frequency intercept in the Nyquist plot corresponds to the cell Ohmic resistance, denoted as HFR. Assuming negligible contact and electronic resistance between layers, the HFR is equivalent to membrane $\left(\right.$ Nafion $\left.^{\circledR} 112\right)$ Ohmic resistance. In the absence of mass transfer limitations, the diameter of the semicircle observed in the Nyquist plot corresponds to charge transfer resistance $\left(R_{\mathrm{ct}}\right)$ due to the Faradaic process. In this case, the resistance primarily arises from the slow kinetics of the $\mathrm{O}_{2}$ reduction reaction (ORR), since the $\mathrm{H}_{2}$ oxidation reaction (HOR) is very facile when pure $\mathrm{H}_{2}$ is used as the fuel.

In systems with high ionic resistance in the electrode, a $45^{\circ}$ line at high frequency is observed. ${ }^{4}$ This feature associated with high electrode ionic resistance is not prominently observed at high RH unless the electrode is poorly designed. A transmission line model is used for determination of the electrode ionic resistance in the absence of mass transport resistance. ${ }^{4}$ The porosity of the electrode is accounted for in the transmission line model by the use of a series (rungs) of distributed circuit elements.

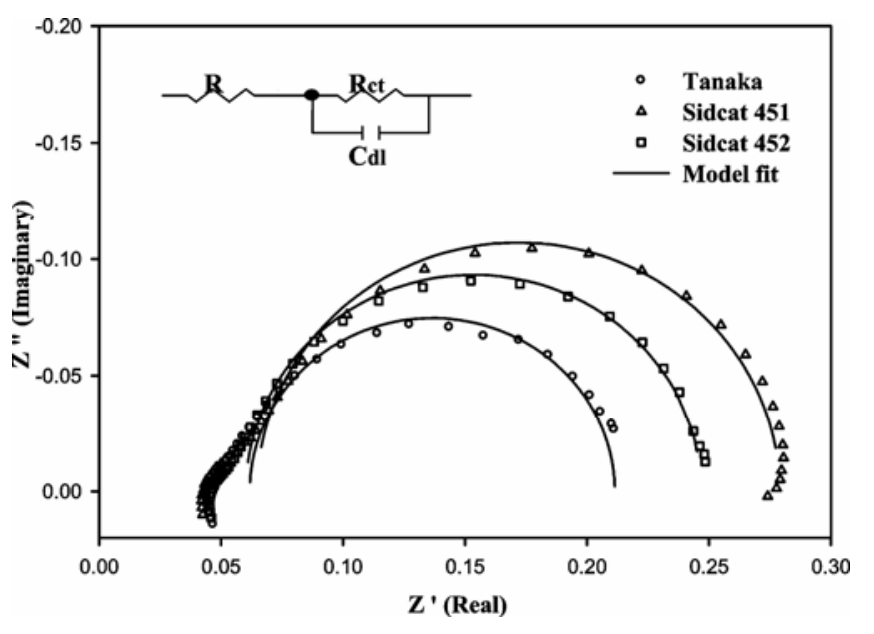

Figure 8. Nyquist plots for MEAs prepared with high Pt loading catalysts under $\mathrm{H}_{2} / \mathrm{O}_{2}$ operation at $80^{\circ} \mathrm{C}$ and $75 \% \mathrm{RH}$ with a constant current of $50 \mathrm{~mA} / \mathrm{cm}^{2}$ and $2 \mathrm{~mA} / \mathrm{cm}^{2}$ amplitude. Points indicate experimental data and lines represent model fits.

The electrode/electrolyte double layer capacitance can be estimated either using a Randles circuit or from the characteristic frequency if the charge transfer resistance $\left(R_{\mathrm{ct}}\right)$ is known. In some cases, the effect of mass transport is observed in the spectra and is accounted for by including a Warburg impedance $(W)$ element in the equivalent circuit model. Mass transfer effects are seen in very thick or poorly designed electrodes and/or when the oxidant concentration at the catalyst surface is low.

Figure 7 shows the Nyquist plot for MEAs prepared with ETEK 5, SIDCAT 405 and SIDCAT 410 catalysts. On close inspection, the spectra for all the three MEAs show two semicircles, although this is not distinctly seen at first glance. The first semicircle corresponds to the Faradaic reaction (ORR), while the second semicircle is attributed to the Warburg impedance caused due to finite $\mathrm{O}_{2}$ diffusion (onset of mass transfer limitations). The catalysts used to construct these MEAs were Pt supported on either carbon $(\mathrm{C})$ or on a $\mathrm{C}-\mathrm{TiO}_{2}$ support. The metal loading on a weight percentage basis was very low in all cases as can be gleaned from table 1. Therefore to yield the desired Pt loading of $0.4 \mathrm{mg} / \mathrm{cm}^{2}$ on the cathode, the electrode thickness was approximately 80 micrometers for ETEK 5 and SIDCAT 405 and 40 micrometers for SIDCAT 410. These electrodes were significantly thicker than the typical 10 micrometer thick electrodes used in MEAs prepared with $\sim 40-50 \mathrm{wt} \% \mathrm{Pt} / \mathrm{C}$ that are the industry standard. The resistance to $\mathrm{O}_{2}$ transport in these 
thicker electrodes is significant even at low current densities (reaction rates) and this mass transfer limitation is responsible for the presence of the second semicircle in the impedance spectrum.

To extract desired Ohmic, kinetic and transport parameters, the data were fit to the equivalent circuit models also shown in figure 7 (inset). Initially, a simple Randles circuit comprising of $R_{c t}, C_{d l}$ and $W$ (figure 7a) was used. The experimentally observed data did not match well with the model as seen in figure $7 \mathrm{a}$. The capacitive element was then replaced with a constant phase element (CPE) to obtain the model shown in figure $7 \mathrm{~b}$. A CPE is a distributive element used to account for non-homogeneity in the porous electrode, which is not adequately captured by a simple capacitance element. ${ }^{5}$ It is important to recognize and remember that the CPE introduces an additional adjustable parameter in the exponent (which equals 1 for the case of pure capacitance). As seen in figure $7 \mathrm{~b}$, the equivalent circuit model with a CPE fitted the experimental data fairly well over the entire frequency range. Due to the overlapping between the two semicircles (kinetic and transport loops), precise estimation of the parameters pertaining to Faradaic reaction and diffusion was difficult to achieve (with high sensitivity) and hence is not reported.

Nyquist plots for the second class of MEAs (Tanaka, SIDCAT 451 and SIDCAT 452) are shown in figure 8 . The desired parameters (HFR, $C_{d l}$ and $R_{c t}$ ) were extracted by fitting the experimental data to a simple Randles equivalent circuit model shown in figure 8 (inset). These parameters are tabulated in table 2 . Since the spectra did not show any limitation due to mass transport (unlike as seen in figure 7), the Warburg impedance element was removed from the model. In addition, the measured EIS spectra were also fit to a transmission line (TL) model with 100 rungs to represent the distributive nature of circuit elements. The TL model was deemed useful as it permits estimation of $R_{c l}$ in addition to $C_{d l}$ and $R_{c t .}{ }^{14}$ Estimates of all the three parameters were obtained from the TL model.

Since Nafion ${ }^{\circledR} 112$ was used as the membrane for all MEAs, the HFR obtained were very similar. The MEA with Tanaka catalyst exhibited the lowest resistance to ORR $\left(R_{c t}\right)$ and the MEA with SIDCAT 451 exhibited the highest resistance to ORR. SIDCAT 452 shows an intermediate $R_{c t}$ value. These results were consistent with our previously published MEA performance data ${ }^{2}$ and with the electro- chemically active surface areas (as measured using cyclic voltammetry) obtained using these electrocatalysts (see above). The higher charge transfer resistance of SIDCAT catalysts was attributed to differences in the carbon base between the TKK and SIDCAT electrocatalysts and to the influence of addition of $\mathrm{TiO}_{2}$ support, which is not an effective catalyst for ORR, on the activity of Pt. The increase in $\mathrm{TiO}_{2}$ content from 5\% (SIDCAT 451) to $10 \%$ (SIDCAT 452) increased the double layer capacitance (see table 2) and both the $\mathrm{TiO}_{2}$-containing SIDCAT catalysts exhibited a higher double layer capacitance than the TKK catalyst. The $R_{c t}$ and $C_{d l}$ values estimated from both the Randles circuit and TL model were nearly identical, as observed in table 2 .

The total ionic resistance in the catalyst layer is represented as $R_{c l}$ and was estimated from the TL model and reported in table 2 . The corresponding voltage loss is equivalent to $i^{*} R_{c l} / 3{ }^{4}$ The term $R_{c l} / 3$ is termed the effective proton transport resistance in the cathode $\left(R_{e}\right)$ (assuming negligible contribution from the anode to the overall ion transport resistance). The trends in $R_{c l}$ values are in agreement with the performance curves obtained with the various MEAs. ${ }^{2}$ For instance, SIDCAT 451 with $R_{c l}=$ $90 \mathrm{~m} \Omega$ exhibited low performance while the performance obtained with SIDCAT 452 and Tanaka catalysts were similar. The estimates of $R_{c l}$ obtained were higher than expected, especially given the optimized Nafion ${ }^{\circledR}$ ionomer loading of $30 \mathrm{wt} \%$ used in the electrodes and the relatively high inlet $\mathrm{RH}(75 \%)$.

\subsection{Steady-state polarization of MEAs}

The effective proton transport resistance in cathode $\left(R_{e}\right)$ was independently estimated from $\mathrm{H}_{2} / \mathrm{O}_{2}$ and $\mathrm{H}_{2}$ /air polarization data using established methods detailed elsewhere. ${ }^{9,10}$ Figure 9 shows the $\mathrm{H}_{2}$ /air polarization data for the SIDCAT 452 MEA along with the resultant of corrections for $R_{m}, R_{e}$ and mass transport (using limiting current estimates). The parameters estimated from the polarization analysis are tabulated in table 3. The use of Nafion ${ }^{\circledR} 112$ for all the MEAs resulted in similar values of $\mathrm{Rm}$. The low Pt loading MEAs (ETEK 5 and SIDCAT 405/410) exhibited higher effective proton transport resistance in cathode $\left(R_{e}\right)$ than the high Pt loading MEAs (Tanaka and SIDCAT 451/452). The primary reason was the higher electrode thickness in the former. 
Table 2. Parameters predicted by fitting experimental data to: (i) a Randles circuit without Warburg impedance, and (ii) a transmission line (TL) model.

\begin{tabular}{lcccccccc}
\hline & & $R_{c l}(\mathrm{~m} \Omega)$ & & \multicolumn{2}{c}{$R_{c t}(\mathrm{~m} \Omega)$} & & & \multicolumn{2}{c}{$C_{d l}(\mathrm{mF})$} \\
\cline { 8 - 9 } \cline { 7 - 8 } \cline { 7 - 8 } MEA & HFR $(\mathrm{m} \Omega)$ & TL model & & Randles & TL model & & Randles & TL model \\
\hline Tanaka & 45 & 53 & & 150 & 150 & & 16.0 & 17 \\
SIDCAT 451 & 43 & 90 & & 214 & 210 & & 20.7 & 22 \\
SIDCAT 452 & 46 & 49 & & 187 & 190 & & 31.5 & 32 \\
\hline
\end{tabular}

HFR, high frequency resistance; $R_{c l}$, catalyst layer resistance; $R_{c t}$, charge transfer resistance; $C_{d l}$, double layer capacitance

Table 3. Values of parameters obtained from $\mathrm{H}_{2} / \mathrm{O}_{2}$ polarization data from $0.1 \mathrm{~mA}$ $\mathrm{cm}^{-2}-100 \mathrm{~mA} \mathrm{~cm}^{-2}$.

\begin{tabular}{lcccc}
\hline MEA & $R_{m}(\mathrm{~m} \Omega)$ & $R_{e}(\mathrm{~m} \Omega)$ & $i_{L}\left(\mathrm{~mA} \mathrm{~cm}^{-2}\right)$ & $\begin{array}{c}\text { Tafel slope } \\
(\mathrm{mV} / \text { decade })\end{array}$ \\
\hline SIDCAT 405 & 28 & 30 & 600 & 104 \\
SIDCAT 410 & 24 & 20 & 900 & 83 \\
ETEK 5 & 25 & 20 & 700 & 90 \\
SIDCAT 451 & 25 & 5 & 900 & 71 \\
SIDCAT 452 & 25 & 5 & 1100 & 69 \\
Tanaka & 19 & 5 & 1100 & 65 \\
\hline
\end{tabular}

$R_{m}$, membrane resistance, $R_{e}$, effective proton transport resistance in cathode, $i_{L}$, air limiting current

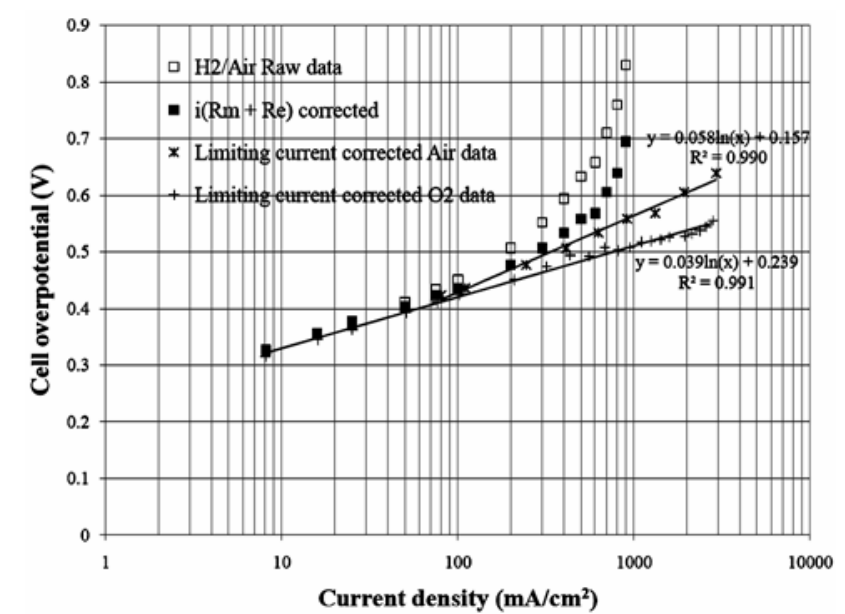

Figure 9. $\mathrm{H}_{2}$ /air polarization data analysis for estimation of effective proton transport resistance at $80^{\circ} \mathrm{C}$ and $75 \%$ RH for SIDCAT 452 MEA. Membrane and electrode Ohmic resistance corrected data $i^{*}\left(R_{m}+R_{e}\right)$ are plotted. The figure also shows polarization data corrected for the limiting current.

SIDCAT 405 with $R_{e}=30 \mathrm{~m} \Omega$ showed the highest electrode resistance and the lowest air limiting current of all; this was consistent with the poor MEA performance exhibited [4]. The higher Tafel slopes (close to that of a double Tafel slope for SIDCAT 405) and the lower limiting current densities observed in the low Pt loading MEAs were clear indicators of mass transport limitations in the electrodes (again, due to higher electrode thickness) when these catalysts were used.

The values of $R_{e}$ for the high Pt loading MEAs were nearly identical (even though the AC impedance measurements predicted higher $\mathrm{Rcl}$ value for SIDCAT 451). The Tafel slopes obtained for this group of MEAs were also similar, ${ }^{2}$ suggesting that the poor performance observed with SIDCAT 451 is related to mass transport limitations. This was further corroborated by the lower limiting current density (of $900 \mathrm{~mA} / \mathrm{cm}^{2}$ ) observed when SIDCAT 451 was used.

In conclusion, the new generation $\mathrm{Pt} / \mathrm{C}-\mathrm{TiO}_{2}$ nanocomposite electrocatalysts have been more completely characterized using techniques such as cyclic voltammetry, rotating disk electrode (RDE) voltammetry, and electrochemical impedance spectroscopy. Importantly, new galvanostatic data confirm the superior stability of these materials against corrosion under anodic polarization conditions rela- 
tive to commercial benchmark fuel cell electrocatalysts.

\section{Acknowledgement}

V R thanks the Department of Chemical and Biological Engineering at Illinoi's Institute of Technology (IIT) for partial funding support.

\section{References}

1. Rajeshwar K, de Tacconi N R, Chenthamarakshan C $\mathrm{R}$, Wampler W A, Carlson T and Lin W Y Photocatalytic deposition of metals and compositions comprising the same U.S. Patent, pending

2. de Tacconi N R, Chenthamarakshan C R, Rajeshwar $\mathrm{K}$, Lin W-Y, Carlson T, Nikiel L, Wampler W A, Sambandam S and Ramani V 2008 J. Electrochem. Soc. 155 B 1102

3. Yuan X, Wang H, Sun J C and Zhang J 2007 Int. J. Hydrogen Energy 324365

4. Makharia R, Mathias M F and Baker D R $2005 \mathrm{~J}$. Electrochem. Soc. 152 A970
5. Barsoukov E, Macdonald J R 2005 Impedance spectroscopy: Theory, experiment and applications (John Wiley \& Sons, Inc) Second edn

6. Lin W-Y, Wei C and Rajeshwar K 1993 J. Electrochem. Soc. 1402477

7. For example: Gasteiger H A, Kocha S S, Sompalli B and Wagner FT 2005 Appl. Catal. B: Environ. 569

8. Wagner F T 2007 private communication (Rajeshwar $\mathrm{K}$ and Wampler $\mathrm{W}$ A)

9. Williams M V, Kunz H R and Fenton J M $2005 \mathrm{~J}$. Electrochem. Soc. 152 A635

10. Sambandam S and Ramani V 2008 Electrochim. Acta 536328

11. McCreery R M 2008 private communication (Rajeshwar K)

12. Paulus U A, Schmidt T J, Gasteiger H A and Behm R J 2001 J. Electroanal. Chem. 495134

13. Schmidt T J and Gasteiger H A 2003 in Handbook of fuel cells-fundamentals, technology and applications (eds) W Vielstich, H A Gasteiger and Lamm A (Chichester, UK: John Wiley \& Sons) Vol 2, pp. 316-333

14. Eikerling M and Kornyshev A A $1999 \mathrm{~J}$. Electroanal. Chem. 475107 